\title{
Predictors of survival and technical success of bronchoscopic interventions in malignant airway obstruction
}

\author{
Cláudia Freitas $^{1,2}$, Mariana Serino ${ }^{1}$, Catarina Cardoso ${ }^{1}$, Sandra Saleiro ${ }^{3}$, Ana Paula Vaz ${ }^{4}$, \\ Hélder Novais-Bastos ${ }^{1,2,5}$, António Morais ${ }^{1,2}$, Adriana Magalhães ${ }^{1}$, Gabriela Fernandes ${ }^{1,2}$
}

${ }^{1}$ Department of Pulmonology, Centro Hospitalar e Universitário São João, Alameda Prof. Hernani Monteiro, Porto, Portugal; ${ }^{2}$ Faculty of Medicine, University of Porto, Alameda Prof. Hernani Monteiro, Porto, Portugal; ${ }^{3}$ Department of Pulmonology, Instituto Português de Oncologia do Porto Francisco Gentil (IPO-Porto) EPE, Rua Dr. António Bernardino de Almeida, Porto, Portugal; ${ }^{4}$ Department of Pulmonology, Unidade de Saúde Local de Matosinhos - Hospital Pedro Hispano, Rua Dr. Eduardo Torres, Senhora da Hora, Portugal; ${ }^{5}$ Instituto de Investigação e Inovação em Saúde (i3S), Instituto de Biologia Molecular e Celular (IBMC), University of Porto, Rua Alfredo Allen, Porto, Portugal

Contributions: (I) Conception and design: C Freitas, A Magalhães, G Fernandes; (II) Administrative support: All authors; (III) Provision of study materials or patients: C Freitas, S Saleiro, AP Vaz, H Novais-Bastos, A Morais, A Magalhães; G Fernandes; (IV) Collection and assembly of data: C Freitas, M Serino, C Cardoso, S Saleiro, AP Vaz, H Novais-Bastos; (V) Data analysis and interpretation: C Freitas, A Magalhães, G Fernandes; (VI) Manuscript writing: All authors; (VII) Final approval of manuscript: All authors.

Correspondence to: Cláudia Freitas. Department of Pulmonology, Centro Hospitalar e Universitário São João, Alameda Prof. Hernani Monteiro, 4200319 Porto, Portugal. Email: claudiaasfreitas@gmail.com.

Background: Malignant airway obstruction (MAO) leads to quality of life impairment and increased mortality. Interventional bronchoscopy allows airway patency restoring, leading to a better survival. We investigated predictors of survival and successful bronchoscopic intervention among MAO patients.

Methods: This observational prospective study enrolled 100 patients who were newly diagnosed with MAO. Survival was estimated with Kaplan-Meier method and curves compared by log-rank test. Multivariate analyses were performed using Cox proportional hazard models. Univariate and multivariate logistic regression were used for odds ratio calculation.

Results: A proportion of $73 \%$ of the patients were male with a median age was 62.5 years (range, 21-88 years). Lung cancer was the most common primary malignancy (74\%). The majority had single (61\%), endoluminal (62\%) lesions and were classified as grade III in Myer Cotton scale (57\%). The most used techniques comprised mechanical debulking $(n=81)$ and laser therapy $(n=68)$. Twenty-two airway stents were placed. While eleven patients were considered untreatable, technical success was achieved in $78 \%$. Haemorrhage was the most common acute complication (16\%). No deaths occurred as a result of the procedure. Median global survival was 8 months. Adjusting for age and Eastern Cooperative Oncology Group Performance Status (ECOG), extrinsic compression or mixed airway obstructions [hazard ratio $(\mathrm{HR})=2.075 ; \mathrm{P}=0.012$ ], successful bronchoscopic intervention $(\mathrm{HR}=0.468 ; \mathrm{P}=0.025)$ and initiation of cancer treatment $(\mathrm{HR}=0.373$; $\mathrm{P}=0.006)$ were independent predictors of survival. The absence of distal airway patency on thoracic CT was independently associated with failure of the intervention [odds ratio $(\mathrm{OR})=0.013 ; \mathrm{P}<0.001$ ].

Conclusions: Interventional bronchoscopy has proven to be an efficient and safe strategy to manage MAO patients. The patients who benefit the most in terms of survival are those with purely endoluminal lesions, in whom technical success was achieved and those whose cancer-specific treatment was initiated. Distal airway patency on thoracic CT predicts the technical success of bronchoscopic intervention.

Keywords: Malignant airway obstruction (MAO); interventional bronchoscopy; airway stenting; cancer care; survival

Submitted Aug 23, 2021. Accepted for publication Nov 13, 2021.

doi: $10.21037 /$ jtd-21-1393

View this article at: https://dx.doi.org/10.21037/jtd-21-1393

$\wedge$ ORCID: 0000-0002-7162-414X.

(C) Journal of Thoracic Disease. All rights reserved. 


\section{Introduction}

Airway obstruction is a potential life-threatening complication of malignancy that leads to quality of life impairment and increased mortality (1-3). The true prevalence of malignant airway obstruction (MAO) in primary lung cancer is not known but it is estimated to occur in up to $30 \%$ of the patients over the course of the disease, as a result of local invasion or advanced stage disease. Also, other organs malignancies such as breast, colon, thyroid, renal cancers present with endobronchial metastases in about $1-4 \%(4-8)$.

Due to its significant implications in patients' outcomes, MAO requires early recognition and prompt treatment. Surgery is potentially curative, however only possible in a limited number of patients depending on location and extension of the lesion, disease stage and overall medical condition $(9,10)$. Systemic treatments or radiation therapy may take time to be effective in reducing the tumour (11). Thus, interventional bronchoscopy allow restoring airway patency in order to palliate symptoms, prevent atelectasis and post-obstructive pneumonia, leading to a better quality of life and survival $(1,10,12,13)$.

Although complications resulting from bronchoscopic interventions in $\mathrm{MAO}$ are not frequent, they are extremely serious and may include bleeding, hypoxia, airway perforation, respiratory failure and death $(8,12,14)$. Moreover, when airway stenting is required to achieve adequate airway patency, this strategy must be balanced with the associated long-term complications $(10,15)$.

In order to better define which MAO patients actually benefit from bronchoscopic interventions, we prospectively investigated predictors of survival and technical success among these patients.

We present the following article in accordance with the STROBE reporting checklist (available at https://dx.doi. org/10.21037/jtd-21-1393).

\section{Methods}

\section{Study design and participants}

This observational prospective study aimed to enroll 100 adult patients who were newly diagnosed with MAO, defined as occlusion of $\geq 50 \%$ of the trachea, mainstem bronchi, bronchus intermedius, or a lobar bronchus (12). The recruitment occurred between January 2019 and April 2021 in Centro Hospitalar Universitário de São João (CHUSJ), a reference center for interventional bronchoscopy in Porto, Portugal. All the participants were followed-up until death or end of data collection (June 2021). The study was conducted in accordance with the Declaration of Helsinki (as revised in 2013). Written informed consent was obtained from all the participants. This study was approved by the Ethics Committee of CHUSJ (No. 388/18).

\section{MAO evaluation and bronchoscopic interventions}

MAO were firstly evaluated with a thoracic computed tomography (CT) and, in most of cases, the first bronchoscopic approach was a flexible bronchoscopy in order to determine MAO characteristics and its classification in purely endoluminal lesion, pure extrinsic lesion causing airway compression, or mixed lesions. Under general anaesthesia, patients were intubated with rigid bronchoscope (RB) (Karl Storz, Tuttlingen, Germany) and manual jet ventilation through the bronchoscope was used. Mechanical debulking with RB and/or forceps was used to remove the endoluminal component. Haemostasis before and during mechanical debulking and endoluminal tumour ablation were performed using a diode laser (Multidiodeendolaser 30, Intermedic Arfran, Barcelona, Spain). Airway dilation, with RB or balloon was performed if necessary. After endoluminal tumour intervention, the airway patency was evaluated and if not satisfactory due to extrinsic compression, airway stenting was considered either using metallic (Boston Scientific, Massachusetts, USA) or Dumon silicone stents (Novatech, LaCiotat, France) (16). The type of the stent as well as its size and shape were selected depending on obstruction location and length.

\section{Data collection}

Patients' demographic data, performance status using the Eastern Cooperative Oncology Group (ECOG) Performance Status, smoking habits, comorbidities, oncologic disease characteristics (primary site of malignancy, histology and staging), MAO features based on both CT scan and bronchoscopy including location, type of obstruction (endoluminal, extrinsic compression or mixed), severity according to Myer-Cotton (17), length and distal airway patency (absence of distal tumour infiltration) were recorded. Techniques used during bronchoscopic intervention, residual airway obstruction and distal patency and all complications that occurred during bronchoscopic intervention were described. The need for additional 
bronchoscopic interventions, oncologic treatment strategy and survival were further documented.

\section{Outcomes}

As a primary outcome, survival was considered as the time from the first bronchoscopic intervention until death or until the end of data collection. Technical success was defined as the reopening of the airway lumen to $>50 \%$ of the normal diameter and a connection to a viable area of distal lung by bronchoscopy as previously proposed (12) and was considered a secondary outcome.

\section{Statistics}

Categorical and continuous variables were described as absolute (n) and relative frequencies, and median and minimum and maximum values, respectively. Median follow-up time was calculated using the reverse KaplanMeier method. Survival was estimated with KaplanMeier method and curves were compared by log-rank test. In addition, univariate and multivariate analyses were performed using Cox proportional hazard models for survival. For predictors of technical success, univariate and multivariate logistic regression was used for crude and adjusted odds ratio (OR) calculation. 95\% confidence intervals (95\% CI) were calculated for median survival, hazard ratios (HR) and OR. All data were analysed using the Statistical Package for the Social Sciences (SPSS, IBM Corp.) software, v. 25.0, and statistical differences were considered significant when $\mathrm{P}<0.05$.

\section{Results}

\section{Baseline features}

During the study period, 232 patients were screened for eligibility and 129 met the inclusion criteria. Of these, 11 were excluded due to loss to follow-up and 18 due to incomplete registries. A total of 100 patients were analysed. Table 1 shows the baseline features, bronchoscopic intervention modalities and complications of the included patients. The majority were males (73\%) and were classified as ECOG $0-1$ (75\%). The median age was 62.5 years (range, 21-88 years). Sixty-three patients had at least one comorbidity, being arterial hypertension and chronic obstructive pulmonary disease (COPD) the most frequent. Lung cancer was the most common primary malignancy
(74\%), at various disease stages (I-II, $\mathrm{n}=6$; III, $\mathrm{n}=27$; IV, $\mathrm{n}=41$ ). Lung histological subtypes included squamous cell carcinoma $(n=32)$, adenocarcinoma $(n=22)$, carcinoid $(n=8)$, small-cell lung carcinoma $(n=6)$, large cell carcinoma $(n=3)$, adenosquamous carcinoma $(\mathrm{n}=1)$, pleomorphic carcinoma $(\mathrm{n}=1)$ and non-small cell carcinoma not otherwise specified $(\mathrm{n}=1)$. Extrapulmonary cancers were either stage III or IV disease. MAO at time of cancer diagnosis occurred in sixty patients $(60 \%)$. The remainders were diagnosed during cancer progression with a median of 14.0 months (range, 3.0-210.0 months) after initial diagnosis. Regarding bronchoscopic features, the majority had single (61\%), endoluminal (62\%) lesions and were classified as grade III in Myer Cotton scale (57\%). Median length was $3.0 \mathrm{~cm}$ (range, $0.5-7.5 \mathrm{~cm}$ ). Five patients had combined bronchoesophageal fistula. Pre-procedure thoracic CT showed atelectasis and airway infiltration distal to the obstruction in 51 and 18 patients, respectively. Two patients had no lung lesions or enlarged lymph nodes identified on pre-procedure thoracic CT. Detailed descriptive data is presented in Table S1.

\section{Bronchoscopic intervention and complications}

Concerning the first procedure, the most used techniques comprised mechanical debulking $(\mathrm{n}=81)$ and laser therapy $(n=68)$. Twenty-two airway stents were placed in the first intervention (silicone: 12; metallic:11; Y shape: 4). Median procedure time was $30 \mathrm{~min}$ (range, 15-90 min). Technical success was achieved in $78 \%$. Eleven patients were considered untreatable after bronchoscopic evaluation. Among those whose intervention was tried but failed $(\mathrm{n}=11)$, eight showed no distal airway patency and four had a residual obstruction more than $50 \%$. Haemorrhage was the most common acute complication (16\%). It was severe only in one patient, who required selective endotracheal intubation and mechanical ventilation in order to protect the airway. All other cases presented moderate bleeding which required only local haemostatic measures such as cold-saline or/and adrenaline instillation and laser photocoagulation. No deaths occurred as a result of the procedure. Long-term stent complications were frequent: mucostasis $(n=6)$, tumor in-growth $(n=4)$ and migration $(\mathrm{n}=3)$, all treated with additional bronchoscopic procedures.

\section{Additional treatment strategies and follow-up}

The median follow-up time was 14 months (95\% CI, 11.2-16.8 months). The majority of the patients underwent 
Table 1 Baseline and MAO features, bronchoscopic intervention modalities and complications

\begin{tabular}{|c|c|}
\hline Features & Value $(n=100)$ \\
\hline \multicolumn{2}{|l|}{ Baseline } \\
\hline Age, years & $62.5[21-88]$ \\
\hline Gender, male & 73 \\
\hline \multicolumn{2}{|l|}{ ECOG } \\
\hline $0-1$ & 75 \\
\hline$\geq 2$ & 25 \\
\hline Former or current smoker & 75 \\
\hline Any comorbidities & 63 \\
\hline \multicolumn{2}{|l|}{ Primary malignancy } \\
\hline Lung cancer & 74 \\
\hline Esophagus & 11 \\
\hline Colorectal & 5 \\
\hline Others (miscellaneous) & 10 \\
\hline \multicolumn{2}{|l|}{ MAO } \\
\hline \multicolumn{2}{|l|}{ Location } \\
\hline Localized lesion & 61 \\
\hline Trachea & 12 \\
\hline Mainstem bronchus & 34 \\
\hline Bronchus intermedius & 8 \\
\hline Lobar bronchus & 7 \\
\hline Extended lesion & 39 \\
\hline Trachea plus bronchus/bronchi & 20 \\
\hline Both mainstem bronchus & 7 \\
\hline $\begin{array}{l}\text { Mainstem bronchus plus lobar bronchus/ } \\
\text { bronchi }\end{array}$ & 12 \\
\hline \multicolumn{2}{|l|}{ Type } \\
\hline Endoluminal & 62 \\
\hline Extrinsic compression & 4 \\
\hline Mixed & 34 \\
\hline \multicolumn{2}{|l|}{ Myer Cotton grade } \\
\hline III (71-99\%) & 57 \\
\hline IV (100\%) & 43 \\
\hline Length, $\mathrm{cm}$ & $3.0(0.5-7.5)$ \\
\hline \multicolumn{2}{|l|}{ Morphology } \\
\hline Exophytic & 41 \\
\hline Infiltrative & 20 \\
\hline Mixed & 35 \\
\hline
\end{tabular}

Table 1 (continued)
Table 1 (continued)

\begin{tabular}{l} 
Features \\
\hline Bronchoscopic interventions \\
Number of bronchoscopies (inspection alone and \\
interventional) per patient
\end{tabular}

1

No. of bronchoscopic interventions per patient

1

2

$\geq 3$

Modalities

Mechanical debulking

Dilation

Laser

Stenting

Stenting in $1^{\text {st }}$ procedure

Stenting type

Silicone

Metallic

Y

Technical success

Complications

During or peri-procedure

Hemorrhage

Hypoxia

Hemodynamic instability

Arrhythmia

Tracheal laceration

Long-term stent complications

$\begin{array}{lc}\text { Mucostasis } & 6 \\ \text { Tumor in-growth } & 4 \\ \text { Migration } & 3 \\ \text { eaths during follow-up } & 55\end{array}$

Categorical variables are presented as absolute frequencies (n). Continuous variables are presented as median [minimum, maximum]. MAO, malignant airway obstruction; ECOG, Eastern Cooperative Oncology Group Performance Status. 
local (i.e., surgery, radiotherapy) $(\mathrm{n}=30)$ and/or systemic therapies $(n=68)$, while $19 \%$ received best supportive care. Each patient underwent a median of 2 (range, 1-14) bronchoscopies (inspection alone and interventional) and 1 (range, 1-9) interventions. Overall, a total of 28 stents were placed during the study period. A stent was placed in the first procedure in 22 patients (silicone: 12; metallic:10; Y shape: 4). In addition, six patients initially managed without stenting required this strategy during the study period (silicone: 5; metallic:1; Y shape: 2). During the follow-up, stent was removed in three patients after systemic treatment initiation.

\section{Survival}

Median global survival after the first bronchoscopic intervention was 8.0 months (95\% CI, 4.9-11.0 months). Survival curves for potential predictors of survival are represented in Figure 1. Uni- and multivariate Cox proportional hazard regression analysis are shown in Table 2. Adjusting for age and ECOG, type of obstruction, technical success achieved in the first bronchoscopic intervention and cancer-specific treatment independently predicted survival among patients with MAO. Extrinsic compression or mixed airway obstructions were associated with poor survival when comparing with purely endoluminal MAO (HR =2.075; 95\% CI: 1.175-3.665; P=0.012). Factors associated with a better survival included successful bronchoscopic intervention $(\mathrm{HR}=0.468 ; 95 \%$ CI: $0.241-0.909 ; \mathrm{P}=0.025)$ and initiation of local or systemic cancer treatment (HR $=0.373 ; 95 \%$ CI: 0.184-0.757; $\mathrm{P}=0.006$ ).

\section{Successful bronchoscopic intervention}

Table 3 shows the logistic regression analysis for predictors of technical success during the first bronchoscopic procedure. In univariate analysis, the absence of distal airway patency on thoracic CT $(\mathrm{P}=0.008)$ was associated with technical failure. Also, the increasing length of the obstruction was associated with reduced likelihood of technical success $(\mathrm{P}=0.021)$. In multivariate analysis, absence of distal airway patency on thoracic CT (OR $=0.013$; 95\% CI: $0.002-0.076$; $\mathrm{P}<0.001)$ independently predicted the success of the intervention.

\section{Discussion}

In this study, MAO was successfully and safely relieved by bronchoscopic intervention, allowing subsequent cancer treatment in most of the patients. In fact, the efficacy and safety of interventional bronchoscopy in the management of this potentially life-threatening cancer-related complication have been extensively recognized $(8,12,14)$.

The technical success of interventional bronchoscopy reported in the literature is about $85-90 \%$ or higher, independently of the primary malignancy $(8,12-14,18-21)$. Our slightly lower success rate $(78 \%)$ is explained by our inclusion criteria. In fact, we included patients with newly diagnosed MAO, including those in whom bronchoscopic intervention was not possible due to bronchoscopic lesions' characteristics $(n=11)$. The technical success excluding those cases is approximately $90 \%$, which is concordant to the literature. However, procedure and anesthesia-related risks together with the lack of success in certain cases makes the selection of the patients essential in order to identify the candidates who actually benefit from this intervention $(22,23)$. Thus, we prospectively investigated which factors predicted survival and technical success among MAO patients referred to bronchoscopic intervention.

We showed that purely endoluminal lesions, successful relief of the airway obstruction in the first intervention and the initiation of cancer-specific treatment independently improved survival among MAO patients. Our results show that patients with lesions with an extrinsic compression component have twice the chance of dying than those with endoluminal lesion. In fact, mixed lesions or those with extrinsic compression were previously associated with decreased survival, either in primary lung cancer or in extrapulmonary malignancies $(8,14,24)$. While endoluminal lesions are usually successfully treated with mechanical debulking and/or with laser therapy, lesions with extrinsic compression component often require stenting to achieve patency, which was previously associated with long-term complications and poorer survival $(22,24)$. The high frequency of long-term stent complications observed in our study strongly corroborates this fact. Although airway stenting is far from being ideal, it can be the only option available to manage airway extrinsic compression and it serves as a bridge until systemic therapies achieve adequate response. Even in lesions without extrinsic compression, stenting seems to lead to long lasting symptom improvement and reduce unattended bronchoscopies being beneficial mainly after first-line systemic treatment failure (25). Pros and cons should be balanced by an experienced multidisciplinary team and the decision of stent placement 

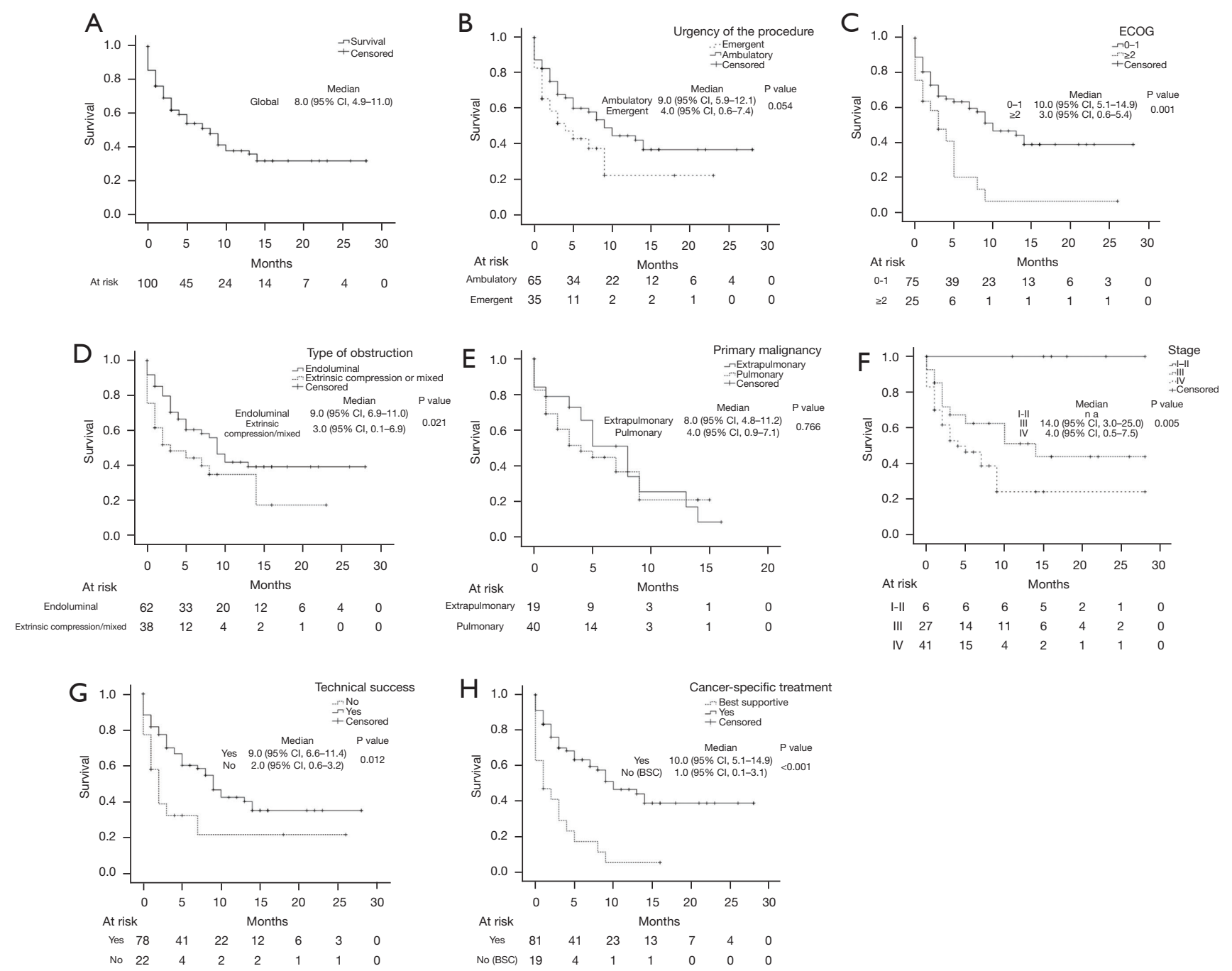

Figure 1 Kaplan-Meyer curves for (A) global survival after the first bronchoscopic intervention ( $\mathrm{n}=100)$; and according to (B) urgency of the procedure (emergent, $\mathrm{n}=35 v s$. ambulatory, $\mathrm{n}=65$ ); (C) ECOG (0-1, $\mathrm{n}=75 v s$. $\geq 2, \mathrm{n}=25$ ); (D) type of obstruction (endoluminal, $\mathrm{n}=62$ vs. extrinsic compression or mixed, $\mathrm{n}=38$ ); (E) primary malignancy (lung excluding carcinoid, $\mathrm{n}=40$ vs. extrapulmonary, $\mathrm{n}=19$ ) among stage $\mathrm{IV}$ patients ( $\mathrm{n}=59)$; (F) stage (I-II, n=6; III, n=27; IV, n=41) among lung cancer patients ( $\mathrm{n}=74)$; (G) technical success on the first procedure (yes, $\mathrm{n}=78$ vs. no, $\mathrm{n}=22$ ); (H) cancer-specific treatment initiation (yes, $\mathrm{n}=81$ vs. best supportive care, $\mathrm{n}=19$ ). ECOG, Eastern Cooperative Oncology Group Performance Status; CI, confidence interval.

must be individualized $(10,15)$.

A successful therapeutic bronchoscopy definitely improves survival among MAO patients (13,19-21,26). Concordantly with Giovacchini et al., we found that in MAO patients who underwent a successful bronchoscopic intervention the risk of death was reduced in about $50 \%$ when compared to the unsuccessful group (21). Besides respiratory failure resolution, the relief of airway obstruction may prevent haemoptysis and post-obstructive pneumonia thus, diminishing the risk of fatal complications.
Nevertheless, the initiation of cancer-specific treatment is a crucial factor to improve overall survival of MAO patients and this study highlights the role of bronchoscopic intervention as a bridge to more definitive treatments, whose beneficial effects are often inconsistent and delayed. Initiating an anti-tumoral treatment increased survival from 1 to 10 months, when compared to best supportive care. As reported in previous studies, patients in whom cancer treatments were not performed, survival decreased $(8,14,18,19)$. Despite patients who received best supportive 
Table 2 Univariate and multivariate cox regression analysis for survival after the first bronchoscopic intervention

\begin{tabular}{|c|c|c|c|c|c|c|}
\hline \multirow{2}{*}{ Variables } & \multicolumn{6}{|c|}{ Survival after bronchoscopic intervention } \\
\hline & HR & $95 \% \mathrm{Cl}$ & $P$ value & $\mathrm{HR}$ & $95 \% \mathrm{Cl}$ & $P$ value \\
\hline Age (<65 vs. $\geq 65$ years) & 1.759 & $1.029-3.006$ & 0.039 & 3.355 & $1.059-10.630$ & 0.115 \\
\hline ECOG ( $\geq 2$ vs. $0-1$ ) & 2.436 & $1.358-4.370$ & 0.003 & 1.064 & $0.507-2.235$ & 0.870 \\
\hline Primary malignancy (Lung vs. others) & 0.611 & $0.343-1.091$ & 0.096 & - & - & - \\
\hline Location (extended vs. single) & 0.873 & $0.501-1.519$ & 0.630 & - & - & - \\
\hline $\begin{array}{l}\text { Type of obstruction (mixed/extrinsic compression } \\
\text { vs. endoluminal) }\end{array}$ & 1.831 & $1.060-3.163$ & 0.030 & 2.075 & $1.175-3.665$ & 0.012 \\
\hline Myer Cotton grade (IV vs. III) & 0.831 & $0.484-1.426$ & 0.501 & - & - & - \\
\hline Cancer-specific treatment (yes vs. BSC) & 0.307 & $0.171-0.551$ & $<0.001$ & 0.373 & $0.184-0.757$ & 0.006 \\
\hline $\begin{array}{l}\text { Urgency of the procedure (ambulatory vs. } \\
\text { emergent) }\end{array}$ & 0.595 & $0.340-1.042$ & 0.069 & - & - & - \\
\hline
\end{tabular}

Table 3 Univariate and multivariate logistic regression analysis for technical success after bronchoscopic intervention

\begin{tabular}{|c|c|c|c|c|c|c|}
\hline \multirow{3}{*}{ Variables } & \multicolumn{6}{|c|}{ Technical success } \\
\hline & \multicolumn{3}{|c|}{ Univariate analysis } & \multicolumn{3}{|c|}{ Multivariate analysis } \\
\hline & OR & $95 \% \mathrm{Cl}$ & $P$ value & OR & $95 \% \mathrm{Cl}$ & $P$ value \\
\hline Smoke status (yes vs. no) & 1.164 & $0.399-3.399$ & 0.781 & - & - & - \\
\hline Location (extended vs. localized) & 0.903 & $0.344-2.369$ & 0.835 & - & - & - \\
\hline Myer Cotton grade (IV vs. III) & 0.433 & $0.165-1.135$ & 0.089 & - & - & - \\
\hline Length (centimeters) & 0.631 & $0.427-0.934$ & 0.021 & 0.715 & $0.422-1.213$ & 0.214 \\
\hline Absence of distal airway patency (yes vs. no) & 0.227 & $0.076-0.678$ & 0.008 & 0.013 & $0.002-0.076$ & $<0.001$ \\
\hline
\end{tabular}

$\mathrm{Cl}$, confidence interval; OR, odds ratio.

care presented poorer survival, bronchoscopic intervention should still be considered since it may be the only way to achieve symptomatic relief and provide better quality of life.

Although higher ECOG patients presented poorer survival on univariate analysis, this was not confirmed when adjusting for other factors, contradicting previous studies $(14,19,22)$. However, Shin et al. also reported that poor performance status was not associated with increased mortality and hypothesize that patients' poor general condition may have been improved immediately after treatment (8). In fact, poor performance status may be strictly related to untreated cancer and significant airway obstruction. When cancer treatment is started and MAO relieved, performance status may improve (27) and longer survival may be achieved. Bronchoscopic intervention should not be restricted to current optimal performance status individuals. Instead, careful patient evaluation is necessary to understand which factors contribute to a poor 
overall condition and if those are potentially manageable.

Bronchoscopic techniques used in this series reflect local practices and include mechanical debulking, laser therapy, dilation and stent placement. Since this is a single center study, the comparison of different techniques was not possible. Nevertheless, distal airway patency visualized on CT was independently associated to successful bronchoscopic intervention. This finding was also demonstrated by Giovacchini et al. in a retrospective study that highlighted the importance of early radiographic identification of MAO and prompt therapeutic intervention (21). In fact, our results show that acutely ill patients, i.e., those who underwent an emergency procedure tended to have poorer survival when compared with those who had an elective/ ambulatory procedure which supports the relevance of an early diagnosis to allow a planned procedure. CT scan is essential in evaluating MAO before intervention in order to characterize the lesion, define its extent and assess potential existing extraluminal compression and, therefore, plan treatment strategies $(7,28)$. Similarly to our findings, the infiltration of the downstream airways was the most common cause of technical failure among MAO patients who underwent bronchoscopic intervention (19).

Although the present study presents a prospective design, important limitations include the small sample size and its unicentric nature. Still, since it was conducted in a single reference center for interventional bronchoscopy, all the patients were managed by the same experienced team of interventional pulmonologists avoiding the bias that might be caused by different regional clinical practices and/or preferences, leading to a more homogenous patient approach. Moreover, novel systemic cancer treatments have been developed in the last years and this progress significantly impacted survival. This series consistently reflect this current advance since the recruitment occurred very recently and in a short period of time. Unfortunately, symptoms and quality of life were not addressed in this work but deserve further investigation.

In conclusion, interventional bronchoscopy has proven to be an efficient and safe strategy to manage patients with MAO and can be the only way to gain time until anti-tumoral therapies exert its effect. The patients who benefit the most in terms of survival are those with purely endoluminal lesions, in whom technical success was achieved in the first bronchoscopic procedure and patients whose cancer-specific treatment was initiated. Definitely, when airways distal to the lesion are patent on thoracic CT trying to open the airways is justified and recommended since it represents a predictor of bronchoscopic intervention success.

\section{Acknowledgments}

The authors thank all the staff of Bronchoscopy Unit of CHSUJ, including doctors, nurses and medical assistants. Funding: None.

\section{Footnote}

Reporting Checklist: The authors have completed the STROBE reporting checklist. Available at https://dx.doi. org/10.21037/jtd-21-1393

Data Sharing Statement: Available at https://dx.doi. org/10.21037/jtd-21-1393

Conflicts of Interest: All authors have completed the ICMJE uniform disclosure form (available at https://dx.doi. org/10.21037/jtd-21-1393). The authors have no conflicts of interest to declare.

Ethical Statement: The authors are accountable for all aspects of the work in ensuring that questions related to the accuracy or integrity of any part of the work are appropriately investigated and resolved. The study was conducted in accordance with the Declaration of Helsinki (as revised in 2013). Written informed consent was obtained from all the participants. This study was approved by the Ethics Committee of CHUSJ (No. 388/18).

Open Access Statement: This is an Open Access article distributed in accordance with the Creative Commons Attribution-NonCommercial-NoDerivs 4.0 International License (CC BY-NC-ND 4.0), which permits the noncommercial replication and distribution of the article with the strict proviso that no changes or edits are made and the original work is properly cited (including links to both the formal publication through the relevant DOI and the license). See: https://creativecommons.org/licenses/by-nc-nd/4.0/.

\section{References}

1. Oviatt PL, Stather DR, Michaud G, et al. Exercise capacity, lung function, and quality of life after interventional bronchoscopy. J Thorac Oncol 2011;6:38-42.

2. Amjadi K, Voduc N, Cruysberghs Y, et al. Impact of 
interventional bronchoscopy on quality of life in malignant airway obstruction. Respiration 2008;76:421-8.

3. Chhajed PN, Baty F, Pless M, et al. Outcome of treated advanced non-small cell lung cancer with and without central airway obstruction. Chest 2006;130:1803-7.

4. Saji H, Furukawa K, Tsutsui H, et al. Outcomes of airway stenting for advanced lung cancer with central airway obstruction. Interact Cardiovasc Thorac Surg 2010;11:425-8.

5. Marchioni A, Lasagni A, Busca A, et al. Endobronchial metastasis: an epidemiologic and clinicopathologic study of 174 consecutive cases. Lung Cancer 2014;84:222-8.

6. Kreisman H, Wolkove N, Finkelstein HS, et al. Breast cancer and thoracic metastases: review of 119 patients. Thorax 1983;38:175-9.

7. Ernst A, Feller-Kopman D, Becker HD, et al. Central airway obstruction. Am J Respir Crit Care Med 2004;169:1278-97.

8. Shin B, Chang B, Kim H, et al. Interventional bronchoscopy in malignant central airway obstruction by extra-pulmonary malignancy. BMC Pulm Med 2018;18:46.

9. Wood DE. Management of malignant tracheobronchial obstruction. Surg Clin North Am 2002;82:621-42.

10. Murgu SD, Egressy K, Laxmanan B, et al. Central Airway Obstruction: Benign Strictures, Tracheobronchomalacia, and Malignancy-related Obstruction. Chest 2016;150:426-41.

11. Nihei K, Ishikura S, Kawashima M, et al. Short-course palliative radiotherapy for airway stenosis in non-small cell lung cancer. Int J Clin Oncol 2002;7:284-8.

12. Ost DE, Ernst A, Grosu HB, et al. Therapeutic bronchoscopy for malignant central airway obstruction: success rates and impact on dyspnea and quality of life. Chest 2015;147:1282-98.

13. Razi SS, Lebovics RS, Schwartz G, et al. Timely airway stenting improves survival in patients with malignant central airway obstruction. Ann Thorac Surg 2010;90:1088-93 .

14. Kim BG, Shin B, Chang B, et al. Prognostic factors for survival after bronchoscopic intervention in patients with airway obstruction due to primary pulmonary malignancy. BMC Pulm Med 2020;20:54.

15. Folch E, Keyes C. Airway stents. Ann Cardiothorac Surg 2018;7:273-83.

16. Dumon JF. A dedicated tracheobronchial stent. Chest 1990;97:328-32.

17. Myer CM 3rd, O'Connor DM, Cotton RT. Proposed grading system for subglottic stenosis based on endotracheal tube sizes. Ann Otol Rhinol Laryngol 1994;103:319-23.

18. Jeon K, Kim H, Yu CM, et al. Rigid bronchoscopic intervention in patients with respiratory failure caused by malignant central airway obstruction. J Thorac Oncol 2006;1:319-23.

19. Guibert N, Mazieres J, Lepage B, et al. Prognostic factors associated with interventional bronchoscopy in lung cancer. Ann Thorac Surg 2014;97:253-9.

20. Stratakos G, Gerovasili V, Dimitropoulos C, et al. Survival and Quality of Life Benefit after Endoscopic Management of Malignant Central Airway Obstruction. J Cancer 2016;7:794-802.

21. Giovacchini CX, Kessler ER, Merrick CM, et al. Clinical and radiographic predictors of successful therapeutic bronchoscopy for the relief of malignant central airway obstruction. BMC Pulm Med 2019;19:219.

22. Ost DE, Ernst A, Grosu HB, et al. Complications Following Therapeutic Bronchoscopy for Malignant Central Airway Obstruction: Results of the AQuIRE Registry. Chest 2015;148:450-71.

23. Grosu HB, Eapen GA, Morice RC, et al. Stents are associated with increased risk of respiratory infections in patients undergoing airway interventions for malignant airways disease. Chest 2013;144:441-9.

24. Verma A, Goh SK, Tai DYH, et al. Outcome differences between recanalized malignant central airway obstruction from endoluminal disease versus extrinsic compression. Lasers Med Sci 2019;34:955-62.

25. Dutau H, Di Palma F, Thibout Y, et al. Impact of Silicone Stent Placement in Symptomatic Airway Obstruction due to Non-Small Cell Lung Cancer - A French Multicenter Randomized Controlled Study: The SPOC Trial. Respiration 2020;99:344-52.

26. Mahmood K, Wahidi MM, Thomas S, et al. Therapeutic bronchoscopy improves spirometry, quality of life, and survival in central airway obstruction. Respiration 2015;89:404-13.

27. Catarata MJP, Saleiro S, Araújo VS. Outcomes of Airway Stents in the Palliative Care of Patients With Cancer. Am J Hosp Palliat Care 2021;38:19-24.

28. Shiau M, Harkin TJ, Naidich DP. Imaging of the central airways with bronchoscopic correlation: pictorial essay. Clin Chest Med 2015;36:313-34, ix-x.

Cite this article as: Freitas $\mathrm{C}$, Serino $\mathrm{M}$, Cardoso $\mathrm{C}$, Saleiro $\mathrm{S}$, Vaz AP, Novais-Bastos H, Morais A, Magalhães A, Fernandes G. Predictors of survival and technical success of bronchoscopic interventions in malignant airway obstruction. J Thorac Dis 2021;13(12):6760-6768. doi: 10.21037/jtd-21-1393 


\section{Supplementary}

Table S1 Detailed baseline and MAO features, bronchoscopic intervention modalities and complications

\begin{tabular}{|c|c|}
\hline Features & $n=100$ \\
\hline \multicolumn{2}{|l|}{ Baseline } \\
\hline \multicolumn{2}{|l|}{ Smoking status } \\
\hline Never & 25 \\
\hline Former or current smoker & 75 \\
\hline \multicolumn{2}{|l|}{ Comorbidities } \\
\hline COPD & 25 \\
\hline Asthma & 3 \\
\hline OSA & 2 \\
\hline Fibrotic interstitial lung disease & 2 \\
\hline Hypertension & 43 \\
\hline Atrial fibrillation & 6 \\
\hline Heart failure & 13 \\
\hline Diabetes mellitus 2 & 9 \\
\hline Cerebrovascular disease & 2 \\
\hline GERD & 5 \\
\hline Chronic renal failure & 4 \\
\hline Chronic liver disease & 5 \\
\hline Other neoplastic disease & 13 \\
\hline \multicolumn{2}{|l|}{ Primary malignancy } \\
\hline Lung & 74 \\
\hline Esophagus & 11 \\
\hline Colorectal & 5 \\
\hline Head and neck & 2 \\
\hline Liver & 2 \\
\hline Breast & 2 \\
\hline Gynecological & 2 \\
\hline Lymphoma & 1 \\
\hline Thyroid & 1 \\
\hline \multicolumn{2}{|l|}{ Stage } \\
\hline I & 1 \\
\hline ॥ & 5 \\
\hline III & 34 \\
\hline IV & 60 \\
\hline
\end{tabular}

Table S1 (continued)
Table S1 (continued)

\begin{tabular}{|c|c|}
\hline Features & $n=100$ \\
\hline \multicolumn{2}{|l|}{ MAO } \\
\hline \multicolumn{2}{|l|}{ Bronchoscopic features } \\
\hline \multicolumn{2}{|l|}{ Myer Cotton grade } \\
\hline $\mathrm{I}(\leq 50 \%)$ & 0 \\
\hline II (51-70\%) & 0 \\
\hline III (71-99\%) & 57 \\
\hline IV (100\%) & 43 \\
\hline Bronchoesophageal fistula & 5 \\
\hline \multicolumn{2}{|c|}{ Pre-procedure CT imaging features } \\
\hline Atelectasis on CT & 51 \\
\hline Distal airway patency & 82 \\
\hline \multicolumn{2}{|l|}{ Bronchoscopic intervention } \\
\hline \multicolumn{2}{|l|}{ Modalities } \\
\hline Mechanical debulking & 81 \\
\hline Dilation & 23 \\
\hline Balloon & 2 \\
\hline Rigid bronchoscope & 21 \\
\hline Laser & 68 \\
\hline Stenting & 28 \\
\hline Stenting in $1^{\text {st }}$ procedure & 22 \\
\hline \multicolumn{2}{|l|}{ Stenting type } \\
\hline Silicone & 17 \\
\hline Metallic & 11 \\
\hline \multicolumn{2}{|l|}{ Stenting shape } \\
\hline Tubular & 22 \\
\hline Y & 6 \\
\hline
\end{tabular}

Categorical variables are presented as absolute frequencies (n). Continuous variables are presented as median (minimum, maximum). MAO, malignant airway obstruction; ECOG, Eastern Cooperative Oncology Group Performance Status; COPD, chronic obstructive pulmonary disease; OSA, obstructive sleep apnea; GERD, gastroesophageal reflux disease. 